\title{
Biased interpretation in perfectionism and its modification
}

\section{Article}

Accepted Version

Yiend, J., Sauvlich, G., Coughtrey, A. and Shafran, R. (2011)

Biased interpretation in perfectionism and its modification. Behaviour Research and Therapy, 49 (12). pp. 892-900. ISSN 0005-7967 doi: https://doi.org/10.1016/j.brat.2011.10.004 Available at https://centaur.reading.ac.uk/31320/

It is advisable to refer to the publisher's version if you intend to cite from the work. See Guidance on citing.

To link to this article DOI: http://dx.doi.org/10.1016/j.brat.2011.10.004

Publisher: Elsevier

All outputs in CentAUR are protected by Intellectual Property Rights law, including copyright law. Copyright and IPR is retained by the creators or other copyright holders. Terms and conditions for use of this material are defined in the End User Agreement.

\section{www.reading.ac.uk/centaur}

\section{CentAUR}

Central Archive at the University of Reading

Reading's research outputs online 
Biased interpretation in perfectionism and its modification

\author{
Jenny Yiend ${ }^{1}$, George Savulich ${ }^{1}$, Anna Coughtrey ${ }^{2}$ and Roz Shafran ${ }^{2}$ \\ Department of Experimental Psychology, University of Oxford
}

\footnotetext{
${ }^{1}$ Now at King's College London.

${ }^{2}$ Now at the University of Reading.
}

Corresponding Author: Jenny Yiend, PO 63, Institute of Psychiatry, De Crespigny

Park, London SE5 8AF. Tel: 07977978655 


\begin{abstract}
Perfectionism is a transdiagnostic construct associated with a range of diagnoses, including depression, eating disorders and obsessive compulsive disorder. Treatments that directly target perfectionist cognitions have been shown to successfully reduce associated pathologies. However, the way in which they do this is not clear. We set out to assess the role of one candidate mechanism of action, namely the cognitive process of interpretation of ambiguity. In one experiment we looked for associations between biased interpretation and perfectionism. In a second, we manipulated interpretations, thereby providing a strong test of their aetiological significance. Results from the first experiment confirmed the presence of biased interpretation in perfectionism and demonstrated that these are highly specific to perfection-relevant information, rather than reflecting general negativity. The second experiment succeeded in manipulating these perfection-relevant interpretations and demonstrated that one consequence of doing so is a change in perfectionist behaviour. Together, these data experimentally demonstrate that biased interpretation of perfection-relevant ambiguity contributes to the maintenance of perfectionism, but that it is also possible to reverse this. Clinical implications include the identification of one likely mechanism of therapeutic change within existing treatments, as well as identification of an appropriate evidence-based focus for future treatment development. Targeting underlying functional mechanisms, such as biased interpretation, has the potential to offer transdiagnostic benefits.
\end{abstract}

Keywords: training, cognitive bias modification, bias, perfectionism, interpretation, behaviour change, transdiagnostic processes 
Introduction

Recent interest in transdiagnostic processes (Fairburn, Cooper, \& Shafran, 2003; Fairburn, Cooper, \& Doll, 2009; Allen, McHugh, \& Barlow, 2008; Norton, 2008) encourages an approach which bypasses traditional diagnostic categories. The transdiagnostic view points to common cognitive mechanisms which maintain a range of different expressions of an underlying psychopathology. Perfectionism is one such transdiagnostic construct. It can be a significant problem in its own right and is associated with psychopathologies including eating disorders (Fairburn et al., 1998; Fairburn, Welch, Doll, Davies, \& O'Connor, 1997), depression (Blatt, Zuroff, Bondi, Sanislow, \& Pilkonis, 1998; Shahar, Blatt, Zuroff, \& Pilkonis, 2003), and obsessive compulsive disorder (Coles, Frost, Heimberg, \& Rheaume, 2003; Hamli et al., 2005). High levels of perfectionism are predictive of poor treatment outcomes and lower satisfaction with treatment (Blatt et al., 1998; Shahar et al., 2003). Converging clinical evidence increasingly suggests that perfectionism is an underlying risk factor for Axis 1 psychopathology.

Perfectionism has been previously viewed as a self-oriented unidimensional construct (Burns; 1980; Pacht, 1984) but researchers now favour a multidimensional approach (e.g. Ashby \& Rice, 2002; DiBartolo, Li, \& Frost, 2008; Hewitt \& Flett, 1990, 1991; Frost et al., 1990; Dunkley, Zuroff, \& Blankstein, 2003; Terry-Short, Owens, Slade, \& Dewey, 1995; Hill et al., 2004; Pearson \& Gleaves, 2006; Rice \& Preusser, 2002; Slaney, Rice, Mobley, Trippi, \& Ashby, 2001). Multidimensional factors include parental expectations, personal standards and concerns over mistakes (Frost, Marten, Lahart, \& Rosenblate, 1990). Perfectionism is thought to have a complex relationship with well being. Both adaptive and maladaptive features have been identified (Hamachek, 1978; Grzegorek, Slaney, Franze, \& Rice, 2004) and 
positive aspects of perfectionism are thought to be related to those features which reflect high standards and achievement striving (Dunkley, Blankstein, Masheb, \& Grilo, 2006; Blankstein \& Dunkley, 2002; Dunkley, Blankstein, Zuroff, Leece, \& Hui, 2006). Some authors argue that perfectionism becomes clinically relevant when the setting of excessively high standards (see Kobori, Hayakawa \& Tanno, 2009 for evidence of this) interacts with overly critical self-evaluation (Boone, Soenens, Braet, \& Goossens, 2010; Shafran, Cooper, \& Fairburn, 2002). These authors argue that clinical perfectionists set unrealistic goals which they have difficulty meeting, perceive their failures personally and suffer more overtly negative consequences. Although it is clear that there is no single consensus on the best definition of perfectionism, most researchers now adopt a multidimensional conceptualization and are united in their acknowledgement of the clinical utility and importance of the construct.

The importance of negatively biased interpretations for diagnostic psychopathologies is widely recognised, both empirically (Blanchette \& Richards, 2010) and theoretically (Mathews \& Mackintosh, 2000) and recent work underlines their aetiological significance (Salemink, van den Hout, \& Kindt, 2007). Most research to date has focussed on anxious (Yiend, 2004; Mathews \& MacLeod, 1994; Williams, Watts, MacLeod, \& Mathews, 1997) or depressed (Lawson \& MacLeod, 1999; Mogg et al., 1994) populations as well as other diagnostic categories (Eating Disorders: Cooper, 1997; Social Phobia: Beard \& Amir 2009). Experimental evidence for interpretative biases associated with perfectionism is however, absent. Our first study was therefore designed to seek experimental evidence for the interpretative biases thought to be associated with perfectionism and to identify their level of specificity. Specificity is an important question to address since interpretative biases could be mere epiphenomena of co-ocurring variations in anxiety and depression. Interpretation biases were therefore measured both for content specifically tailored for its relevance to perfectionism, as well as more generally positive or negative emotional material, known to be sensitive to biased interpretation in anxiety and depression. In addition 
we assessed performance on measures of behaviour designed to reflect perfectionism, as well as differences in general task performance.

\section{Experiment 1}

The aim of Experiment 1 was to identify and characterise naturally occurring interpretation biases associated with perfectionism. The degree of content specificity was assessed by comparing generally positive or negative interpretations of emotionally ambiguous information with perfection specific interpretations of perfection relevant material (material which permitted interpretation in either a perfectionist or non perfectionist direction). We hypothesized that high and low perfectionists would interpret perfection relevant material in a perfectionist and non perfectionist direction respectively, but would not differ in their interpretations of general emotionally ambiguous information. We further hypothesized that highperfectionists would exhibit a greater degree of perfectionist behaviours than lowperfectionists on three perfection relevant behavioural tasks, above and beyond any generic differences in performance on a control task.

Method

\section{Participants}

Participants were selected from the University of Oxford based on their scores on the Perfectionism Subscale of the Dysfunctional Attitude Scale (Weissman \& Beck, 1978; DAS). Forty students, 20 high perfectionist (6 males, 14 females; mean age $=22.50$ $\mathrm{SD}=2.88 ;$ mean DAS score $=73.23 \mathrm{SD}=5.34)$ and 20 low perfectionist $(9$ males, 11 females; mean age $=20.35 \mathrm{SD}=1.93$; mean DAS score $=34.10 \mathrm{SD}=5.49$ ), were recruited. Other inclusion criteria were fluency in English; no current or past history of psychiatric disorder; and not receiving psychological or psychiatric treatment currently or for the past 6 months.

Interpretation bias task

Participants read passages of text that were ambiguous in terms of either emotional or perfectionist meaning. Participants' interpretation of passages was 
measured using a similarity rating test for items reflecting each possible meaning of the original passages and also for unrelated control ('foil') items (Mathews \& Mackintosh, 2000; Eysenck et al., 1991). On each trial a three line ambiguous passage was presented along with an identifying title. The final word of the last sentence was presented as a fragment which participants had to complete correctly by giving the first missing letter. This was followed by a neutral comprehension question (yes/no response, with feedback) about the factual content of the passage. This procedure ensures that the meaning of the passages is processed, while maintaining the inherent ambiguity. Twenty emotionally ambiguous and 20 perfection relevant passages were presented in random order.

Subsequently, interpretation was assessed for each passage by presenting two disambiguating sentences one reflecting the negative or perfectionist interpretation (negative or perfectionist target) and the other reflecting the positive or non perfectionist interpretation (positive or non perfectionist target). Two 'foil' sentences per passage were also presented that were of positive/ non perfectionist or negative/ perfectionist meaning. Foil sentences were loosely related to the passage, but were not factually possible interpretations of the original. As in previous versions of this task these were designed to assess response bias (i.e. the tendency to endorse any schema congruent information). The dependent measure was participants' rating of each sentence for similarity in meaning to the original passage on a 1 (very different in meaning) to 4 (very similar in meaning) scale.

Emotionally ambiguous items were taken from Eysenck et al. (1991) and comprised 10 social (situations involving one's partner, family, friends, etc.) and 10 physical (situations describing physical activity of the self or others) sets. Corresponding perfection relevant materials were specifically designed for this study ${ }^{1}$, defining a perfectionist interpretation as arising when $(a)$ the exceptionally high standard required by perfectionists is not achieved and (b) not achieving this standard has direct implications for self worth (Shafran et al., 2002). For each passage two target and two foil sentences were created. For example a

\footnotetext{
${ }^{1}$ Items may be obtained from the first author upon request
} 
perfectionist test item, entitled 'Birthday Cake' read 'It is the night of your mother's $50^{\text {th }}$ birthday party. Her favourite dessert is banana cream cake with rainbow sprinkles. After baking the cake, you open the cabinet and realize you only have chocolate...' followed by the word completion 's-rinkl-s' ('sprinkles') and the question 'Is it the night of your mothers 80th birthday?' (correct answer: NO). The associated disambiguating target and foil sentences for this item would be: 'You are pleased with the cake you baked and feel complimented' (positive target, perfectionist interpretation); 'You are disappointed with the cake you baked and feel criticized' (negative target, non perfectionist interpretation); 'You paid close attention in cooking class' (positive foil, unrelated positive interpretation); 'You did not pay close attention in cooking class' (negative foil, unrelated negative interpretation).

Mean perfectionism ratings for newly developed items $(1=$ totally perfectionist to 7 $=$ totally non perfectionist) from 6 independent raters were as follows: non perfectionist targets $=6.3$, non perfectionist foils $=6.4$; perfectionist targets $=1.5$, perfectionist foils $=1.5$. Comparisons of perfectionism ratings between targets and foils of a given direction (perfectionist, non perfectionist) revealed no significant differences $(t(5)=.04 p=.97$ perfectionist items; $t(5)=.36 p=.73$ non perfectionist items,) whereas comparisons of direction within each sentence type (target and foil) revealed sentences were well differentiated $(t(5)=24.38 p<.001$ targets; $t(5)=18.93 p<.001$ foils $)$.

\section{Behavioural tasks}

Bead sorting. This task has previously been used to measure checking behaviour in clinical disorders associated with perfectionism (Bouchard, Rheaume, \& Ladoucuer, 1999). Participants were presented with 40 coloured beads ( 5 beads in each of 8 colours) and asked to classify them into 12 empty narrow-necked bottles. Instructions specified to pick up one bead at a time and put each type of bead into a different bottle as quickly but as accurately as possible. Bottles were semi-transparent making it difficult to see whether classification errors had been made. After 1 minute participants were stopped and given the option to check the bottles in order to correct any mistakes, for as long as they desired. Dependent measures were number of participants choosing to check and time spent checking. 
Jumping to conclusions. Doubts about actions were assessed using a modified version of the jumping to conclusions task (Huq, Garety, \& Hemsley, 1986). Participants were presented with an opaque bag with 100 beads and told it contained either 30 black beads and 70 white beads or 30 white beads and 70 black beads. Participants then reached into the bag without looking into it and removed one bead at a time, continuing to take out as many beads as needed in order to confidently decide which ratio the bag contained. Time taken to decide, total number of beads picked, and total number of beads picked of each colour were recorded.

Copying. This task was designed specifically for the current study to assess personal standards by measuring attention to detail, spatial organization, and thoroughness when reproducing complex information. Participants were asked to copy a passage of text and a complex geometrical figure as neatly, clearly, and accurately as possible. Participants were timed without limit. An array of tools (paper, a ruler, eraser, coloured pencils, protractor, and compass) was available during the task. Measures of performance were time taken to complete the task and independent ratings of copying quality.

Control. General task performance was measured by asking participants to clear the workstation in preparation for the next session. Participants were asked to empty all 12 bottles, place the beads into a dish, and insert the 12 bottles into 2 carriers. Time taken to complete this task was measured, as an indicator of general performance speed.

\section{Procedure}

Participants completed the computerised test of interpretation bias based on previous work (Eysenck et al., 1991; Mathews \& Mackintosh, 2000; Yiend \& Mackintosh, 2004). Forty ambiguous passages were presented self-paced in randomised order. Participants were instructed to read the text and use it to help them complete a related word fragment and answer a question that was presented at the end of each passage. Immediately following the last passage, a similarity rating test presented target and foil sentences independently for rating. Items were presented 
randomised in blocks of 4 together with the title of the associated passage. Blocks were presented in fixed order corresponding to the order of presentation of original passage. Participants were asked to indicate on a 4 -point scale $(1=$ very different in meaning, 4 = very similar in meaning) how similar each item was to the meaning of the corresponding passage.

The behavioural tasks (bead sorting, jumping to conclusions, copying and control task) were then administered in a fixed or counterbalanced order. Lastly, participants completed the Beck Depression Inventory (Beck, Ward, Mendelson, Mock, \& Erbaugh, 1961)), a short version of the Spielberger Trait-Anxiety Inventory (STAI: Spielberger, Gorsuch, Lushene, Vagg, \& Jacobs, 1983), the Clinical Perfectionism Questionnaire (CPQ; Fairburn, Cooper, \& Shafran, unpublished, cited in Riley et al., 2007), the Hewitt and Flett Multidimensional Perfectionism Scale (MPS; Hewitt \& Flett, 1988), and the Frost Multidimensional Perfectionism Scale (FMPS; Frost et al., 1990).

Results

During analyses, the critical statistical test was the interaction between Group and the Independent factors, for a given dependent variable; follow-up tests were conditional upon the significance of this interaction and its subsequent simple main effects.

\section{Participant Characteristics}

As can be seen from Table 1, the two groups differed on measures of perfectionism, but not on trait anxiety or depression.

\section{INSERT TABLE 1 HERE}

\section{Interpretation Bias Task}

A four-way mixed design ANOVA was conducted on mean similarity ratings, with factors Content (perfectionist relevant, emotional) $\mathrm{x}$ Sentence Type (target, foil) $\mathrm{x}$ Direction (congruent, incongruent) x Group (low-perfectionist, high-perfectionist). 
This revealed a significant 4 -way interaction, $\mathrm{F}(1,38)=7.91, \mathrm{p}=.008$ as well as significant main effects of Sentence Type, $F(1,38)=97.91, p<0.001$ (2.43 vs. 1.93, respectively) and Direction, $F(1)=41.64, p<0.001$ (2.19 vs. 2.17 , respectively). Follow up mixed ANOVAs (Sentence Type x Direction x Group) were conducted for each type of Content separately (perfectionist relevant, emotional). Means for all conditions are shown in Table 2.

\section{INSERT TABLE 2 HERE}

For emotional items the interaction reflecting emotionally biased interpretations was not significant, Sentence Type $\mathrm{x}$ Direction $\mathrm{x}$ Group, $\mathrm{F}(1,38)=0.28$, $p=.6$ whereas for perfectionist relevant items the same interaction was highly significant: Sentence Type x Direction x Group $F(1,38)=10.62, p=.002$. Follow up two-way ANOVAs (Group: high perfectionist, low perfectionist $x$ Direction: perfection congruent, perfection incongruent) were conducted for each Sentence Type (target, foil). These revealed a highly significant Group x Direction interaction for targets, $F(1,38)=12.82, p=.001$ as well as a significant interaction for foils, $F(1,38)$ $=5.98, p=.02$. For targets subsequent independent samples $t$-tests confirmed that high perfectionists rated perfectionist items as more similar to the ambiguous passages previously seen than did low perfectionists, $(t(38)=3.40, p=.002)$. In contrast, the reverse pattern was seen on non perfectionist items; low perfectionists rated these items as more similar to the ambiguous passages previously seen than did high perfectionists, $t(38)=-3.49, p=.001$. The results reflecting the level of content specificity of interpretation bias in perfectionism are illustrated in Figure 1.

\section{INSERT FIGURE 1 HERE}

\section{Behavioural Tasks}

Bead Sorting. The number of participants choosing to check their sorting performance was analysed using a $2 \times 2 \chi^{2}$ (Checking Choice: yes, no x Group: high 
perfectionist, low perfectionist). There was a significant group difference in checking behaviour, in the predicted direction, $\chi^{2}(1)=8.12, p=.004$, showing that significantly more high perfectionists $(15 / 20)$ than low perfectionists $(6 / 20)$ chose to check. Additionally high-perfectionists spent a significantly longer time checking comparing to low, 9.53 vs. 3.88 secs, $t(38)=-2.45, \mathrm{p}=.02$.

Jumping to Conclusions. High-perfectionists removed more beads from the bag before deciding the bead colour ratio than did low perfectionists $(19.80, \mathrm{SD}=11.51$ vs. $13.95, \mathrm{SD}=10.67)$, although the difference just failed to reach significance $\mathrm{t}(38)=$ $-1.67, \mathrm{p}=0.05$. Although time taken to reach a decision was longer for high than low perfectionists $(58.19$ secs, $\mathrm{SD}=35.78$, vs. $45.54 \mathrm{secs}, \mathrm{SD}=36.38)$, the difference was not statistically significant, $t(38)=-1.1, p=0.14$.

Copying. High-perfectionists were significantly slower to complete the copying task than low perfectionists $(1236 \mathrm{sec}, \mathrm{SD}=525$, vs. $677 \mathrm{sec}, \mathrm{SD}=216), t(38)=-$ 4.41, $p<.001$. To assess the quality of performance on the task a standardised, objective procedure was developed for rating the copies. Raters judged copy quality on 7-point Likert scales $(1=$ strongly disagree, 7 = strongly agree $)$ using a transparency of the original superimposed on each replication. Each of the following individual criteria was assessed on this scale: text accuracy, copy positioning, line spacing, shape dimensions, shape colours, and overall impression. Overall mean rating of match to template was then calculated for each copy. Blind ratings were made by one rater and a purposively sampled random subset of these ( 5 of each group) was blind rated by a second rater. Cohen's kappa indicated good agreement between raters, $\mathrm{k}=.65$ and .72 for low and high perfectionist scripts respectively.

Overall mean ratings (scale $1=$ strongly disagree, $7=$ strongly agree) of match to template were $3.95(\mathrm{SD}=1.13)$ for low perfectionists and $5.59(\mathrm{SD}=0.64)$ for highperfectionists. An independent samples $t$-test, $t(38)=5.65$ confirmed this difference to be highly significant $(\mathrm{p}<0.001)$.

Control. An independent samples $t$-test showed that time taken to complete the control task did not differ significantly between groups $(82.55, \mathrm{SD}=13.19$, vs 81.95 $\mathrm{ms}, \mathrm{SD}=14.49$, for low and high perfectionists respectively). 


\section{Discussion}

Experiment 1 used cognitive and behavioural tasks to identify discriminators of high versus low perfectionism. Ambiguous passages were interpreted differently by high and low perfectionists. Whereas high perfectionists were more prone to endorse perfectionist interpretations than were low perfectionists, the reverse pattern was found for non perfectionist interpretations. This pattern of biased interpretation was stronger for perfection relevant information of target sentences than foil sentences and was not found for information reflecting generally emotionally ambiguous information. The high degree of content specificity suggests that the interpretation biases associated with perfectionism are more than simply an epiphenomenon of a more general negative interpretation bias, similar to that found in anxiety and depression. Furthermore as our groups did not differ in their levels of self reported anxiety or depression, it is not possible to attribute the perfectionist interpretation bias observed to these traits. To our knowledge this is the first experimental evidence of biased interpretations in perfectionism.

Marked group differences in behavioural tendencies associated with perfectionism were found across a variety of measures. As predicted, significantly more high than low perfectionists chose to check for mistakes in their bead sorting performance. Of those who did check the high perfectionists spent significantly longer doing so than the low. High-perfectionists also took significantly longer copying complex information, and made significantly better, more accurate matches to the template compared to low-perfectionists. Our global measure of performance speed suggested that differences were not likely to be attributable to wider effects on any motor task.

\section{Experiment 2}

Experiment 1 allowed experimental identification of the naturally occurring biases and behaviours associated with perfectionism. In the second experiment we 
manipulated these interpretations, in order to provide a strong test of their aetiological significance. If maladaptive, perfection-specific interpretation biases are indeed a key maintaining mechanism for perfectionism and its associated disorders (Fairburn et al., 2003), then changing these biases should result in changes in symptom related behaviours. There is a growing literature on manipulating cognitive biases using experimental paradigms. These so called 'cognitive bias modification' (CBM) procedures reveal that biases analogous to those which occur naturally can be induced, generalise to new material (Mathews \& Mackintosh, 2000; Mathews \& MacLeod, 2002; Yiend \& Mackintosh, 2004), produce congruent changes in mood state (Salemink \& van den Hout, 2010; Holmes, Mathews, Dalgleish, \& Mackintosh. 2006), survive over time and across changes in context (Yiend, Mackintosh, \& Mathews, 2005; Mackintosh, Mathews, Yiend, Ridgeway \& Cook, 2006) and decrease vulnerability to negative mood (e.g. Hoppitt, Mathews, Yiend, \& Mackintosh, 2007; Lester, Mathews, Davison, Burgess \& Yiend, 2011; Mathews, Ridgeway, Cook, \& Yiend, 2007; Mackintosh et al., 2006). We therefore chose this method to examine the consequences of manipulating the interpretation biases specific to perfectionism identified in our first experiment.

Biases were induced towards and away from perfectionist interpretations in healthy volunteers following pilot work to develop appropriate perfection relevant induction materials. We hypothesized that induced interpretation tendencies would be deployed to cognitive tests of interpretation involving previously unseen material. We also hypothesized that bias induction would affect behaviour, specifically that inducing non perfectionist interpretations should reduce perfectionist behaviour whereas inducing perfectionist interpretations should increase it. The bead sorting task was chosen as the most appropriate measure of perfectionist behaviour, because of its proven sensitivity both in previous literature and in Experiment 1.

Method

Participants 
Thirty-six (7 males, 29 females; mean age 19.75 SD = 1.86) students were recruited from two local universities. Inclusion criteria were fluency in English; no current or past history of psychiatric disorders and scoring 3 or below on each of 3 Likert scales $(1=$ not at all, $5=$ very $)$ measuring self reported perfectionism, anxiety and depression. Participants were randomised to one of two groups; the first received an induction to make non perfectionist interpretations, while the second was trained to make perfectionist interpretations.

Materials

Two hundred and forty bias induction items and 50 test items were generated based on examples from the clinical work of one author (RS) and tapping domains relevant to perfectionist thinking, including employment, academic experience, social interaction, physical appearance, sporting activities, and domestic situations ${ }^{2}$. For example one perfectionist induction item was entitled 'Cleaning the Car' followed by the text 'You decide to clean your car. You wash the outside but don't have time to do the inside. As you are finishing, you think the job you have done is...p-o-' (poor). The corresponding nonperfectionist induction item would end with a word completion ' $g o-d$ ' (good). The following question read 'Do you think your car is clean enough now?' to which those in the perfectionist induction condition were required to respond 'no' ('yes' in non perfectionist condition). Items were piloted for their ability to induce bias. Inspection of pilot data suggested that items reflecting evaluation of the self appeared to be particularly successful at eliciting biases in both induction directions. One hundred items capturing elements of self evaluation and spanning as wide a range of content as possible were chosen for subsequent use. This was based on the assumption that induced biases would most successfully generalise to other phenomena if as wide as possible a range of different material was used during induction. For test items an item analysis was conducted to identify the 20 most discriminatory (i.e. those items producing the greatest induction congruent difference on target ratings when averaged across pilot participants) which were selected for subsequent use. These were similar in form to the example given in Experiment 1.

\footnotetext{
${ }^{2}$ Bias induction and test materials may be obtained from the lead author upon request.
} 


\section{Procedure}

Participants completed the following trait questionnaires: the Beck Depression Inventory (Beck et al., 1961); a short version of the Spielberger Trait Anxiety Inventory (STAI: Spielberger, et al., 1983) and the Frost Multidimensional Perfectionism Scale (FMPS: Frost et al., 1990). Three further questionnaires were given as part of a separate investigation before participants performed the preinduction bead sorting task. Half the participants were randomly allocated to bias induction in a perfectionist direction and the other half to non perfectionist induction. The details of induction and test were as reported previously (e.g. Mathews \& Mackintosh, 2000; Yiend \& Mackintosh, 2004). Induction involved presenting participants with passages of ambiguous text that they were forced to resolve in a perfectionist or non-perfectionist way by completing disambiguating word fragments and answering questions that reinforced the desired interpretation. A 15 minute filler task (reading passages of neutral descriptive text) was given after induction to reduce any group differences in state mood produced by exposure to valenced material.

A test phase comprising new ambiguous passages was then presented, following the format reported in Experiment 1. Participants rated individual sentences (presented with the title of the passage as a prompt) on a four point scale according to their similarity in meaning to the original text (1: very different in meaning, 4: very similar in meaning). The behavioural task was then repeated. State mood was measured at several points during the session (immediately prior to induction; immediately after induction; between the filler task and the test task and immediately prior to the behavioural task) using visual analogue scales of anxious and depressed mood. Tasks were administered on a PC computer using E Prime version 1.1 software.

Results

\section{Participant Characteristics}

As can be seen from Table 1, the two induction groups did not differ significantly prior to induction on any measure of trait mood (all t's $<1$, p's $>.2$ ). 
Group means scores were: $\mathrm{BDI}=6.9(\mathrm{SD}=5.0), \mathrm{STAI}=13.7(\mathrm{SD}=1.7)$ and FMPS $=$ $90.2(\mathrm{SD}=16.7)$.

\section{Interpretation Bias Test}

Mean ratings for each induction group for targets and foils are shown in Table 2. A three-way ANOVA, Induction (perfectionist, non perfectionist) x Sentence Type (target, foil) x Direction (perfectionist, non perfectionist), revealed a significant main effect of Sentence Type, $F(1,34)=75.36, p<.001$, showing that targets were endorsed as more similar to original passages than foils ( 2.40 vs. 1.69 respectively). Two-way interactions were subsumed within a significant three-way interaction, $F(1,34)=5.38$, $p=.03$. When broken down by Sentence Type (using two way ANOVA's of Direction $\mathrm{x}$ Induction), groups differed in their endorsements of positive and negative sentences for both targets, $F(1,34)=8.18, p=.007, \eta^{2}=.19$ and foils $F(1,34)=6.13, p=.018$, $\eta^{2}=.15$

Individual contrasts showed that, for targets, the two groups differed significantly in the pattern of endorsements for both types of sentence ( $t$ 's $>2, p$ 's $<.05)$. As seen from the means in Table 2, the perfectionist-trained group judged sentences reflecting perfectionist interpretations more similar to the original passage than did the non perfectionist group, and the opposite pattern obtained for sentences reflecting non perfectionist interpretations. For foils the groups differed significantly only on perfectionist sentence types $(t(34)=2.77, p=.01)$, but not on non perfectionist sentence types $(t(34)=-.46, p=.65)$. Thus the three way interaction reflected a tendency for the groups to interpret the ambiguous passages in line with the direction of their induction, and this was particularly clear for the target sentences, that is, those most accurately capturing the possible meanings of the ambiguous texts. To further illustrate this result, induction congruent differences between group mean ratings were calculated then summed across the two sentence types (perfectionist, non perfectionist) within targets and foils separately. This quantifies the total group difference in ratings 
attributable to induction. The total group mean difference in ratings for targets was $0.85^{3}$, whereas for foils it was approximately half this, 0.45 .

\section{State Mood Measures}

Two questions were of interest in relation to state mood during the testing session. Firstly, whether there was any mood change across induction and if so whether this would be congruent with induction direction, as might be predicted from some recent studies (e.g. Yiend \& Mackintosh, 2004). Two way ANOVAs of Time (pre-induction, post-induction) x Induction (perfectionist trained group, non perfectionist trained group) on mood measures (VAS anxiety and depression) showed interactions and main effects were non significant $(F$ 's $<1, p$ 's $>0.6)$.

Secondly, we wished to confirm that groups were matched for state mood prior to post-induction tests of behaviour and interpretation. If not, then any performance differences might arise as a direct consequence of mood change, or be mediated by mood change, as opposed to being directly related to change in cognitive interpretations. Independent $t$-tests comparing mood scores prior to the post induction tests showed there to be no significant group differences, all $t$ 's $<.5, p$ 's $>.4$.

\section{Behavioural Task: Bead Sorting}

The two measures of interest in the behavioural task were the number of participants who chose to check their performance and the amount of time spent checking. Prior to analysis of time spent checking, values of zero were imputed for those individuals who chose not to check. The resulting positively skewed dataset was subjected to a square root transformation. Values of skewness and kurtosis were then within the limits generally considered acceptable for normality. Duration of checking was then analysed using a two way mixed model ANOVA, with factors Time (before induction, after induction) $\mathrm{x}$ Induction (perfectionist induction, non perfectionist induction). The interaction term was significant, $F(1,34)=7.5, p=.01, \eta^{2}=0.18$ and follow up $t$ tests revealed that the group trained in a non-perfectionist direction spent 
significantly less time checking after induction than before, $0.76 \mathrm{~s}(\mathrm{SD}=1.39) \mathrm{vs} 6.71 \mathrm{~s}$ $(\mathrm{SD}=11.68)$ respectively, $t(16)=2.16, p=.05$. The perfectionist-induced group showed no significant change, $\mathrm{t}(16)=-.37, p=.72$ (means: $1.42 \mathrm{~s}, \mathrm{SD}=3.92$ before vs $1.95 \mathrm{~s}$, $\mathrm{SD}=4.37$ after $)$

Numbers of participants choosing to check was analysed by categorising checking behaviour pre- to post-induction into either 'no change', 'less checking' or 'more checking'. Participants who chose to check on both occasions were categorised according to whether the time they spent checking either increased, decreased or did not change ${ }^{4}$. Nineteen individuals (53\%) changed their behaviour after induction and the overall pattern of results is illustrated in Figure 1. Categorical analyses showed there was a significant relationship between checking behaviour and induction group, Fisher's Exact $=7.5, p=.03$. A direct comparison between the more vs less checking categories and induction group, revealed a significant interaction, Fisher's Exact $=6.1, p<.05$. Thus when checking behaviour changed, the direction of change was significantly more likely than not to be in accordance with the induction manipulation ${ }^{5}$. Following non-perfection induction just over half the group ( 0.58 of the total group; 0.9 of those whose behaviour changed) subsequently engaged in less perfectionist behaviour. In contrast following perfection induction around one fifth of the group ( 0.26 of the total group; 0.63 of those whose behaviour changed) subsequently engaged in more perfectionist behaviour. Inspection of the means (see Figure

\footnotetext{
${ }^{4}$ Results remained the same when these participants were categorised as 'no change' (because they chose to check on both occasions). However the analysis is reported using a categorisation taking into account change in checking times because this is arguably a more accurate reflection of actual behaviour change. Analysis of the full dataset shown in Figure 2 (ie including the 'no change' category) produced similar results, Fisher's Exact $=7.5, p=.03$

${ }^{5}$ Follow up Fisher's Exact tests contrasting the two groups for individual behaviours (less, more, no checking) showed a non-significant trend for a group difference on 'less checking' Fisher's Exact = $3.8, p<.09$, and differences for the other categories did not reach significance, possibly due to low power at this level of analysis.
} 
2) suggests that behaviour was harder to change in this group. However for those who did change, this occurred more frequently in the predicted direction (more checking).

\section{INSERT FIGURE 2 ABOUT HERE}

\section{Discussion}

Experiment 2 showed that our induction procedure successfully manipulated perfection relevant interpretations to be typical of perfectionists or non-perfectionists. This was shown by subsequent interpretations of similar but novel ambiguous passages being biased in a direction consistent with the manipulation. Perfectionist trained participants endorsed sentences reflecting perfectionist self evaluations (e.g. anticipation of failure) more readily than did those receiving the opposite induction and non-perfectionist trained participants gave higher ratings to sentences reflecting non perfectionist self evaluations (e.g. anticipation of success) compared to their perfection trained counterparts. This pattern of endorsements was more pronounced for target sentences that reflected possible interpretations of the ambiguous test passages, than it was for foil sentences, which were only remotely related to the test passages, and were designed to capture general tendencies to endorse positive and negative material.

In addition Experiment 2 showed that the induction manipulation had a significant influence on behaviour in the checking task. Those receiving non-perfectionist induction spent significantly less time checking their performance after compared to before induction, consistent with predictions, whereas the perfectionist trained group showed no significant change. This may reflect the training procedures having asymmetrical effects and proxy perfectionist behaviours being inherently harder to introduce than their non- perfectionist equivalents. A categorical analysis of the same data showed that just over half the sample changed their behaviour after induction, and that induction was a significant mediator of the direction of that change. Consistent with predictions, the significant relationship between change in behaviour and induction group reflected a pattern whereby more non-perfection trained individuals reduced their checking, whereas more perfection trained individuals increased their checking. 
While the two analyses of the behavioural data were not independent, inclusion of both adds to the validity of the findings by demonstrating i) that change was exhibited by a number of individuals, rather than being carried by one or two particularly susceptible to induction (categorical analysis) and ii) that the non perfectionist manipulation affected the duration of the relevant behaviour as well its occurrence (continuous data). We are confident that group differences in behaviour (and at cognitive test) were unlikely to be a secondary consequence of differences in transient mood since mood measures taken during testing revealed no significant differences.

\section{General Discussion}

Experiment 1 demonstrated that high-perfectionists, compared to low, have a cognitive bias in interpretation specific to perfectionist materials. They showed significantly more checking behaviour, in line with that previously associated with perfectionism in clinical samples. They also showed significantly greater accuracy and care when asked to reproduce complex material. These behavioural differences occurred in the absence of wider differences in motor execution speed. Experiment 2 demonstrated that the ambiguous text method of inducing biased interpretation could be adapted to manipulate interpretations relevant to perfectionism by showing transfer of induction effects to similar but new material. More importantly it showed that performance on the behavioural task related to perfectionism was significantly altered by the manipulation. Those trained to make nonperfectionist interpretations spent significantly less time checking performance on a sorting task than their perfection trained counterparts. In addition, decisions about whether to check or not changed significantly in opposite directions according to the manipulation received.

These data have important clinical implications. Firstly, they provide the first experimental evidence of biased interpretations in perfectionism, showing also that they are highly content specific and quite unrelated to the equivalent biases commonly observed in depression and anxiety. More importantly, by manipulating these interpretations and showing behaviour change results, we have provided strong support for their aetiological 
significance. Our results imply that perfection-specific interpretation biases are indeed a key maintaining mechanism for perfectionism and its associated disorders. Further clinical implications include the identification of one likely mechanism of therapeutic change within existing treatments, and our data suggest that this should remain the focus of future transdiagnostic treatment approaches.

In addition we have shown that these same biases can be experimentally manipulated with significant consequences for the behaviours associated with them. Our data are some of the first to suggest that altering interpretations of ambiguous material may produce congruent changes in behaviour. This adds an important new domain to the growing range of effects found following bias induction manipulations (Macleod, Koster \& Fox 2009). Evidence of behavioural change provides an additional reason to be optimistic about the potential clinical utility of experimental inductions of interpretation biases. If experimentally altering interpretations has the potential to change behaviour as well as trait mood and vulnerability to stress (as reported in other studies) then the potential clinical benefits of positive manipulations are correspondingly broader than previously suggested.

A notable unpredicted finding suggested by these data is that induction influenced behaviour more strongly in the non perfectionist induction. For example, only this group showed significant effects of the induction procedure on time spent checking. A larger sample size may have lead to significant change occurring within the perfectionist group alone. Another possibility is that adaptive behaviours may be easier to instigate than non adaptive ones ${ }^{6}$. It is also possible that, despite randomisation, the non perfectionism group comprised individuals whose behaviour was inherently more malleable. Only future work will be able to distinguish between these accounts.

\footnotetext{
${ }^{6}$ We do not wish to imply that all checking behaviour is maladaptive, rather that under certain circumstances, including those in the task used here, excessive checking may not serve a useful purpose.
} 
Limitations include that self-report data are particularly vulnerable to general response priming, raising the possibility in other bias modification studies that the manipulation of interpretation may be less important than simple exposure to valenced material. As behaviour is far less susceptible to response priming, the present results suggest that this is unlikely to be the primary mechanism of action in Experiment 2.

There are other limitations to our data. It is important to be cautious in interpreting the present results. Most obviously, it will be important to replicate these data. Future work should use additional measures of perfection related behaviour (see Stoeber, Chesterman \& Tann, 2010; Stoeber \& Eysenck, 2008 for possibilities) to validate the present findings. Careful attention should be paid to co-occurring psychopathology to control for this likely confound. Our sample was preselected to differ on level of perfectionism. It is surprising that the high-perfectionist and low-perfectionist groups did not also report differences in anxiety and depression, given these dimensions' known associations.

Importantly, our data provide new evidence of behavioural change following an experimental manipulation. Nonetheless we acknowledge the small effect observed in differences in checking time between groups. Although perfectionism-related behaviour was associated with better performance on our copying task, perfectionism was also associated with significant costs on other measures such as checking, and speed. This is consistent with Eysenck and colleagues' processing efficiency theory which suggests that true performance is best measured as 'performance effectiveness' which they propose is a function of 'processing efficiency x effort' (Eysenck, Derakshan, Santos \& Calvo, 2007; Eysenck, 1992).Thus although perfectionist performance may be to a high standard (eg. particularly accurate copying) this may come at a significant cost perhaps reflected by the increased time on task and greater tendency to check. In addition, it remains to be seen whether individuals with high levels of perfectionism would show similar changes in cognition and behaviour to those reported in this healthy sample, and this will be an important next step. However, it is apparent that the text based interpretation technique transfers adequately 
from healthy to vulnerable anxious populations (e.g. Mathews et al., 2007) and there is no reason to believe the same would not be true for perfectionism.

Studies such as these will inevitably be limited by uncertainty regarding the number and type of dimensions needed to most parsimoniously capture the perfectionism construct. Our data do not speak to a multidimensional construct and it is a limitation that we cannot determine whether particular subscales of perfectionism were driving these results (or indeed influenced them differentially). This line of work could be extended by conducting further studies of correlational design to identify the respective contributions of different dimensions of perfectionism. Previous research, for example, has stressed the importance of distinguishing between the personal standards and evaluative concerns dimensions of perfectionism (e.g. Dunkley, Blankstein, Masheb, \& Grilo, 2006; Stoeber \& Otto, 2006). Of particular interest, it has been shown that the Dysfunctional Attitude Scale (DAS; Weissman $\&$ Beck, 1978) is a better measure of evaluative concerns than personal standards (Dunkley \& Kyparissis, 2008). Given the previous literature showing that dimensions of personal standards and evaluative concerns have different patterns of relationship with important outcome variables (e.g. classroom studies: Bieling, Israeli, Smith, \& Antony, 2003; Brown et al., 1999; studies on mistakes: Frost et al. 1995; athlete studies: Hill, Hall, \& Appleton, 2010; Stober, Otto, Pescheck, Becker, \& Stoll, 2007), it is surprising that our data did not provide any evidence of a dissociation and that both dimensions correlated highly with the DAS. Although this does not map onto previous conceptualizations of perfectionism that find DAS perfectionism reflects evaluative concerns, it does, however, reflect recent findings that have shown both dimensions are significant in the prediction of eating disorders (Boone, Soenens, Braet, \& Goossens, 2010)'.

An important question when considering experimental procedures aimed towards eventual clinical application, such as these, is the degree of likely therapeutic change and the proportion of individuals likely to benefit. Although it is too early to say in relation to clinical populations, our analyses gave some indication of the proportion of healthy 
individuals whose behaviour was altered in Experiment 2; just over half the sample showed some change and the non-perfectionist manipulation accounted for the majority of these. While this is encouraging, it clearly requires replication in a larger sample and using subclinical or clinical participants. These data illustrate that manipulations that are successful on average, are unlikely to be so for everyone. Critical questions include what determines susceptibility to change and why one direction of change can be more evident than another. The current sample in Experiment 2 was too small to meaningfully explore possible moderators, but these might include, degree of initial interpretation bias, other trait characteristics or comorbidity.

In summary, our results provide the first experimental evidence of the interpretation biases associated with perfectionism. These biases show a high degree of content specificity, with perfectionists making interpretations specifically related to definitions of the construct, over and above interpretations reflecting general positivity or negativity. Two behavioural tasks revealed that perfectionists were more likely to check their own performance and were more thorough when completing a complex copying task, despite general performance speed not differing. In a further experimental manipulation we either increased or decreased interpretations reflecting perfectionism, and showed that the likelihood of engaging in checking behaviour correspondingly increased or decreased. Treatments that directly target perfectionist cognitions have been shown to successfully reduce associated pathologies and the present data suggest one mechanism by which this may occur. Together, these data experimentally demonstrate that biased interpretation of perfection-relevant ambiguity contributes to the maintenance of perfectionism, but that it is also possible to reverse this. Perfectionism is a personality construct which is highly clinically relevant and spans several diagnostic categories. Targeting underlying functional mechanisms related to this construct, such as the biased interpretations we identify and manipulate here, has the potential to offer substantial transdiagnostic benefits. 


\section{Acknowledgements}

We thank Andrew Mathews for comments on the manuscript

We thank Helen Doll for statistical advice on the analyses in Experiment 2.

Professor Roz Shafran was funded by the Wellcome Trust as a Clinical Research Fellow at the time of this work. 


\section{References}

Allen, L.B., McHugh, R.K., \& Barlow, D.H. (2008). Emotional disorders: a unified protocol. In D.H. Barlow (Ed.), Clinical Handbook of Psychological Disorders ( $4^{\text {th }}$ Ed.). New York: The Guilford Press.

Amir, N., \& Kozak, M. J. (2002). Information processing in obsessive compulsive disorder. Frost, Randy O (Ed); Steketee, Gail (Ed), (2002). Cognitive approaches to obsessions and compulsions: Theory and treatment.

Ashby, J. S., \& Rice, K.G. (2002) Perfectionism, dysfunctional attitudes, and self-esteem: A structural equation analysis. Journal of Counseling and Development, 80, 197-203.

Beard, C., \& Amir, N., (2009) Interpretation in Social Anxiety: When meaning precedes Ambiguity? Cognitive Therapy and Research, 33, 406-415.

Beck, A. T., Ward, C. H., Mendelson, M., Mock, J., \& Erbaugh, J. (1961). An inventory for measuring depression. Archives of General Psychiatry, 4, 53-63.

Bieling, P.J., Israeli, A., Smith, J., \& Antony, M.M (2003). Making the grade: the behavioural consequences of perfectionism in the classroom. Personality and Individual Differences, 35 , 163-178.

Blanchette, I., \& Richards, A. (2003) Anxiety and the interpretation of ambiguous information: Beyond the emotion-congruent effect. Journal of Experimental Psychology: General, 132, 294-309.

Blanchette, I., \& Richards, A. (2010). The influence of affect on higher level cognition: A review of research on interpretation, judgment, decision making and reasoning. Cognition and Emotion,

Blankstein, K. R., \& Dunkley, D. M. (2002). Evaluative concerns, self-critical, and personal standards perfectionism: A structural equation modeling strategy. In G. L. Flett, \& P. L. Hewitt (Eds.) Perfectionism: Theory, research, and treatment (pp. 285-315). Washington, DC: American Psychological Association.276-324.

Blatt, S. J., Zuroff, D. C., Bondi, C. M., Sanislow, C. A., 3rd, \& Pilkonis, P. A. (1998). When and how perfectionism impedes the brief treatment of depression: further analyses of the National Institute of Mental Health Treatment of Depression Collaborative Research Program. Journal of Consulting \& Clinical Psychology, 66(2), 423-428.

Boone, L., Soenens, B., Braet, C., \& Goossens, L. (2010). An empirical typology of perfectionism in 
early-to-mid adolescents and its relation with eating disorder symptoms. Behaviour Research and Therapy, 48, 686-691.

Bouchard, C., Rheaume, J., \& Ladouceur, R. (1999). Responsibility and perfectionism in OCD: An experimental study. Behaviour Research and Therapy, 37(3), 239-248.

Brown, E.J., Heimberg, R.G., Frost, R.O., Makris, G.S., Juster, H.R. \& Leung, A.W., 1999.

Relationship of perfectionism to affect, expectations, attributions and performance in the classroom. Journal of Social and Clinical Psychology, 18, 98-120

Burns, D. D. (1980). The perfectionist's script for self-defeat. Psychology Today, 34-51.

Calvo, M. G., Eysenck, M. W. \& Estevez, A. (1994) Ego-threat interpretive bias in test anxiety: OnLine inferences. Cognition and Emotion, 8(2), 127-146.

Coles, M. E., Frost, R. O., Heimberg, R. G., \& Rheaume, J. (2003). "Not just right experiences": perfectionism, obsessive-compulsive features and general psychopathology. Behaviour Research \& Therapy, 41(6), 681-700.

Cooper, M. (1997) Bias in interpretation of ambiguous scenarios in eating disorders. Behaviour Research and Therapy, 35(7), 619-626.

DiBartolo, P.M., Li, C.Y., \& Frost, R.O. (2008). How do the dimensions of perfectionism relate to mental health? Cognitive Therapy Research, 32, 401-417.

Dunkley, D. M., Blankstein, K. R., Masheb, R. M., \& Grilo, C. M. (2006). Personal standards and evaluative concerns dimensions of "clinical" perfectionism: A reply to Shafran et al. (2002, 2003) and Hewitt et al. (2003). Behaviour Research and Therapy, 44(1), 63-84.

Dunkley, D. M., Blankstein, K.R., Zuroff, D.C., Lecce, S. \& Hui, D. (2006). Self-critical and personal standards factors of perfectionism located within the five-factor model of personality. Personality and Individual Differences, 40, 409-420

Dunkley, D.M., \& Kyparissis, A. (2008). What is DAS self-critical perfectionism really measuring? Relations with the five-factor model of personality and depressive symptoms. Personality and Individual Differences, 44, 1295-1305.

Dunkley, D. M., Zuroff, D. C., \& Blankstein, K. R. (2003). Self-critical perfectionism and daily affect: Dispositional and situational influences on stress and coping. Journal of Personality and Social Psychology, 84, 234-252. 
Eysenck, M.W. (1992). Anxiety: The cognitive perspective. Hove: Lawrence Erlbaum Associates.

Eysenck, M. W., Derakshan, N., Santos, R., \& Calvo,M. G. (2007). Anxiety and cognitive performance:Attentional control theory. Emotion, 7(2), 336_353.

Eysenck, M. W., Mogg, K., May, J., Richards, A., \& Mathews, A. (1991) Bias in Interpretation of sentences related to threat in anxiety. Journal of Abnormal Psychology, 100(2), 144-150.

Fairburn, C. G., Cooper, Z., \& Shafran, R. (2003). Cognitive behavioural therapy for eating disorders: a "transdiagnostic" theory and treatment. Behaviour Research and Therapy, 41(5), 509-528.

Fairburn, C. G., Doll, H. A., Welch, S. L., Hay, P. J., Davies, B. A., \& O'Connor, M. E. (1998). Risk factors for binge eating disorder: a community-based, case-control study. Archives of General Psychiatry, 55(5), 425-432.

Fairburn, C. G., Welch, S. L., Doll, H. A., Davies, B. A., \& O'Connor, M. E. (1997). Risk factors for bulimia nervosa. A community-based case-control study. Archives of General Psychiatry, 54(6), 509-517.

Frost, R. O., Marten, P., Lahart, C., \& Rosenblate, R. (1990). The dimensions of perfectionism. Cognitive Therapy And Research, 14(5), 449-468.

Frost, R. O., Novara, C., \& Rheaume, J. (2002). Perfectionism in obsessive compulsive disorder. In R. O. Frost \& G. Steketee (Eds.), Cognitive approaches to obsessions and compulsions: Theory and Treatment.

Grey, S., \& Mathews, A. (2000) 'Effects of training on interpretation of emotional ambiguity', Quarterly Journal of Experimental Psychology, vol.53, no.4, pp.1143-62.

Grzegorek, J., Slaney, R., Franze, S., \& Rice, K. (2004). Selfcriticism, dependency, self-esteem, and GPA satisfaction among clusters of perfectionists and non-perfectionists. Journal of Counseling Psychology, 51, 192-200.

Halmi, K. A., Tozzi, F., Thornton, L. M., Crow, S., Fichter, M. M., Kaplan, A. S., et al. (2005). The relation among perfectionism, obsessive-compulsive personality disorder and obsessivecompulsive disorder in individuals with eating disorders. International Journal of Eating Disorders, 38(4),371-374.

Hamachek, D. (1978). Psychodynamics of normal and neurotic perfectionism. Psychology, 15, 27-33. 
Hertel, P. T., Mathews, A., Peterson, S., \& Kintner, K. (2003). Transfer of training emotionally biased interpretations. Applied Cognitive Psychology, 17(7), 775-784.

Hewitt, P., \& Flett., G. (1991). Perfectionism in the self and social contexts: Conceptualization, assessment, and association with psychopathology. Journal of Personality and Social Psychology, 60, 456-470.

Hewitt, E L., \& Flett, G. L. (1990). Perfectionism and depression: A multidimensional analysis. Journal of Social Behaviour and Personality, 5, 423-438.

Hewitt, P., \& Flett, G. (1989). The multidimensional perfectionism scale: Development and validation. Canadian Psychology, 30, 339.

Hill, A.P., Hall, H.K., \& Appleton, P.R. (2010). A comparative examination of the correlates of selforiented perfectionism and conscientious achievement striving in male cricket academy players. Psychology of Sport and Exercise, 11, 162-168.

Hill, R.W., Huelsman, T.J., Michael Furr, R., Kibler, J., Vicente, B.B., \& Kennedy, C. (2004). A new measure of perfectionism: The perfectionism inventory. Journal of Personality Assessment, $82,80-91$

Hirsch, C., \& Mathews, A. (1997) Interpretative inferences when reading about emotional events. Behaviour Therapy and Research, 35(12), 1123-1132.

Holmes, E., Mathews, A. Dalgleish, T., \& Mackintosh, B. (2006). Positive interpretation training: effects of mental imagery vesus verbal training on positive mood. Behaviour Therapy, 37(3), 237-247.

Hoppitt, L., Mathews, A., Yiend, J., \& Mackintosh, B. (2007) Cognitive Bias Modification: The Critical Role of Active Training in Modifying Emotional Responses. Behavioural Therapy, 41(1), 73-81.

Kobori, O., Hayakawa, M.m \& Tanno, Y. (2009). Do perfectionists raise their standards after success? An experimental examination of the revaluation of standard setting in perfectionism. Journal of Behavioural Therapy and Experimental Psychiatry, 40, 515-521.

Koster, E. H. W., Fox, E., \& Macleod, C. (2009) Introduction to the Special Section on Cognitive Bias Modification in Emotional Disorders. Journal of Abnormal Psychology, 118(1), 1-4.

Lawson, C., \& MacLeod, C. (1999). Depression and the interpretation of ambiguity. Behaviour 
Research and Therapy, 37(5), 463-474.

Lester, K., Mathews, A., Davison, P., Burgess, J. \& Yiend, J. (2011). Modifying cognitive errors promotes cognitive well being: A new approach to bias modification. Journal of Behavior Therapy and Experimental Psychiatry, 42, 298-308.

Mackintosh, B., Mathews, A., Yiend, J., Ridgeway, V., \& Cook, E. (2006). Induced Biases in Emotional Interpretation Influence Stress Vulnerability and Endure Despite Changes in Context. Behavior Therapy, 37(3), 209-222.

Macleod, C., \& Cohen, I. L. (1993) Anxiety and the interpretation of ambiguity: a text comprehension study. Journal of Abnormal Psychology, 102(2), 238-247.

Macleod, C., Koster, E. H. W., \& Fox, E. (2009) Whither Cognitive Bias Modification Research? Commentary on the Special Section Articles. Journal of Abnormal Psychology, 118(1), 89-99.

Mathews, A., \& Mackintosh, B. (2000). Induced emotional interpretation bias and anxiety. Journal of Abnormal Psychology, 109(4), 602-615.

Mathews, A., \& MacLeod, C. (1994). Cognitive approaches to emotion and emotional disorders. Annual Review of Psychology, 45, 25-50.

Mathews, A., \& MacLeod, C. (2002). Induced processing biases have causal effects on anxiety. Cognition \& Emotion, 16(3), 331-354.

Mathews, A., Ridgeway, V., Cook, E., \& Yiend, J. (2007). Inducing a benign interpretational bias reduces trait anxiety. Journal of Behavior Therapy and Experimental Psychiatry, 38(2), 225236.

Mogg, K., Bradley, B. P, Miller, P., Potts, H., Glenwright, J., \& Kentish, J. (1994) Interpretation of Homophones Related to Threat: Anxiety or Response Bias Effects? Cognitive Therapy and Research, 18(5), 461-477.

Morrison, T., Waller, G., \& Lawson, R. (2006). Attributional Style in the Eating Disorders. Journal of Nervous and Mental Disease, 194(4), 303-305.

Murphy, R., Hirsch, C. R., Mathews, A., Smith, K., \& Clark, D. M. (2007). Facilitating a benign interpretation bias in a high socially anxious population. Behaviour Research and Therapy, 45(7), 1517-1529.

Norton, P.J. (2008). An open trial of a transdiagnositc cognitive-behavioural group therapy for anxiety 
disorder. Behaviour Therapy, 39(2), 242-250.

Osamu Kobori, O., Hayakawa, M. \& Tanno, Y. (2009). Do perfectionists raise their standards after success? An experimental examination of the revaluation of standard setting in perfectionism. Journal of Behavior Therapy and Experimental Psychiatry, 40, 515-521

Pacht, A.R. (1984). Reflections on perfection. American Psychologist, 39, 386-390.

Pearson, C. A., \& Gleaves, D. H. (2006). The multiple dimensions of perfectionism and their relation with eating disorder features. Personality and Individual Differences, 41, 225-235.

Rheaume, J., Freeston, M. H., Ladouceur, R., Bouchard, C., Gallant, L., Talbot, F., et al. (2000). Functional and dysfunctional perfectionists: Are they different on compulsive-like behaviors? Behaviour Research and Therapy, 38(2), 119-128.

Rice, K. G., \& Preusser, K. J. (2002). The adaptive/maladaptive perfectionism scale. Measurement and Evaluation in Counseling and Development, 34, 210-222.

Richards, A., \& French, C. C. (1992). anxiety-relationship bias in semantic activation when processing threat/neutral homographs. The quarterly journal of experimental psychology, 45(3), 503-525.

Richards, A., French, C. C., Calder, A. J., Webb, B., Fox, R., \& Young, A. W. (2002) Anxiety Related Bias in the Classification of Ambiguous Facial Expressions. Emotion, 2(3), 273-287.

Salemink, E., \& van den Hout, M. (2010). Trained interpretive bias survives mood change. Journal of Behaviour Therapy and Experimental Psychiatry, 41, 310-315.

Salemink, E., van den Hout, M., \& Kindt, M. (2007) Trained interpretive bias and anxiety. Behaviour Research and Therap, 45(2), 329-340.

Shafran, R., Cooper, Z., \& Fairburn, C. G. (2002). Clinical perfectionism: A cognitive-behavioural analysis. Behaviour Research and Therapy, 40(7), 773-791.

Shafran, R., Cooper, Z., \& Fairburn, C.G. (2003). "Clinical perfectionism" is not "multidimensional perfectionism": A reply to Hewitt, Flett, Besser, Sherry, \& McGree. Behaviour Research and Therapy, 41, 1217-1220.

Shafran, R., \& Mansell, W. (2001) Perfectionism and Psychopathology: a review of research and treatment. Clinical Psychology Review, 21(6), 871-906. 
Shahar, G., Blatt, S. J., Zuroff, D. C., \& Pilkonis, P. A. (2003). Role of perfectionism and personality disorder features in response to brief treatment for depression. Journal of Consulting \& Clinical Psychology, 71(3), 629-633.

Slaney, R. B., Rice, K. G., Mobley, M., Trippi, J., \& Ashby, J. S. (2001). The revised Almost Perfect Scale. Measurement and Evaluation in Counseling and Development, 34, 130-145.

Spielberger, C. D., Gorsuch, R. L., Lushene, R., Vagg, P. R., \& Jacobs, G. A. (1983). Manual for the State-Trait Anxiety Inventory. Palo Alto, CA: Consulting Psychologists Press.

Stoeber, J., Chesterman, D. \& Tarn, T. A. (2010). Perfectionism and task performance: Time on task mediates the perfectionistic strivings-performance relationship. Personality and Individual Differences, 48, 458-462.

Stoeber, J. \& Eysenck, M. W. (2008). Perfectionism and efficiency: Accuracy, response bias, and invested time in proof-reading performance. Journal of Research in Personality, 42, 16731678.

Stoeber, J., \& Otto, K. (2006).Positive conceptions of perfectionism: Approaches, evidence, challenges. Personality and Social Psychology Review, 10, 295-319.

Stoeber, J., Otto, K., Pescheck, E., Becker, C., Stoll, O. (20070. Perfectionism and competitive anxiety in athletes: Differentiating striving for perfection and negative reactions to imperfection. Personality and Individual Differences, 42, 959-969.

Terry-Short, L.A., Owens, R.G., Slade, P.D., \& Dewey, M.E. (1995). Positive and negative perfectionism. Personality and Individual Differences, 18, 663-666.

Turner, C. (2005). Cognitive behavioural processes across psychological disorders: A transdiagnostic approach to research and treatment. British Journal of Clinical Psychology, 44(3), 453.

Wade, T. D., Bergin, J. L., Martin, N. G., Gillespie, N. A., \& Fairburn, C. G. (2006). A Transdiagnostic Approach to Understanding Eating Disorders. Journal of Nervous and Mental Disease, 194(7), 510-517.

Weissman, A., \& Beck, A. (1978). Development and validation of the dysfunctional attitude scale: A preliminary investigation. Paper presented at the annual meeting of the American Educational Research Association (62 ${ }^{\text {nd }}$, Toronto, Ontario, Canada, March 27-31). 
Wilson, E. J., MacLeod, C., Mathews, A., \& Rutherford, E. M. (2006). The Causal Role of Interpretive Bias in Anxiety Reactivity. Journal of Abnormal Psychology, 115(1), 103-111.

Williams, J. M. G., Watts, F. N., Macleod, C. \& Mathews, A. (1997) Cognitive Psychology and Emotional Disorders, $2^{\text {nd }}$ edn. New York: Wiley.

Yiend, J. (Ed.). (2004). Cognition, Emotion and Psychopathology. Cambridge: Cambridge University Press.

Yiend, J., \& Mackintosh, B. (2004). The experimental modification of processing biases. In J. Yiend (Ed.), Cognition, Emotion and Psychopathology. Cambridge: Cambridge University Press.

Yiend, J., Mackintosh, B., \& Mathews, A. (2005). The enduring consequences of experimentally induced biases in interpretation. Behaviour Research and Therapy, 43(6), 779-797. 